\title{
The GST T1 and CYP2E1 genotypes are possible factors causing vinyl chloride induced abnormal liver function
}

Received: 19 November 1996 / Accepted: 17 March 1997

\begin{abstract}
Vinyl chloride monomer (VCM) is hepatotoxic as well as carcinogenic in humans. There are reports that exposure to VCM seems to induce abnormal liver function, liver fibrosis, cirrhosis, portal hypertension, and angiosarcoma of the liver. In vivo, VCM is metabolized by cytochrome P450 2E1 (CYP2E1) to form the electrophilic metabolites, chloroethylene oxide (CEO) and chloroacetaldehyde (CAA), which may either cause cell damage or be further metabolized and detoxified by glutathione S-transferases (GSTs). This study investigated whether or not the genotypes CYP2E1, glutathione S-transferase $\theta$ (GST T1) and $\mu$ (GST M1) correlated with abnormal liver function found in vinyl chloride exposed workers. For this study, 251 workers from five polyvinyl chloride plants were enrolled. The workers were classified into two exposure groups (high and low) and the degree of exposure was determined based on their job titles and airborne VCM concentration. The activity of serum alanine aminotransferase (ALT) was used as the parameter of liver function. The genotypes CYP2E1, GST T1 and GST M1 were determined by polymerase chain reaction and restriction fragment length polymorphism on peripheral white blood cell DNA. Other potential risk factors were also ascertained and the confounding effect was adjusted accordingly. Stratified analyses were used to explore the correlation between the alteration of liver function and the genotypes CYP2E1, GST T1 and GST M1 among the workers exposed to different levels of VCM. The following results were obtained (1) at low VCM exposure, the odds ratio (OR) of positive GST T1 on ab-
\end{abstract}

C.-Y. Huang · K.-L. Huang · T.-J. Cheng · J.-D. Wang Institute of Occupational Medicine and Industrial Hygiene, College of Public Health, National Taiwan University, Taipei, Taiwan

L.-L. Hsieh (ه)

Department of Public Health, Chang Gung College of Medicine and Technology, 259 Wen-Hwa 1 Road,

Kwei San, Tao-Yuan 3332, Taiwan normal ALT was 3.8 (95\% CI 1.2-14.5) but the CYP2E1 genotype was not associated with abnormal ALT. (2) At high VCM exposure, a c2c2 CYP2E1 genotype was associated with increased OR on abnormal ALT (OR 5.4, 95\% CI 0.7-35.1) and positive GST T1 was significantly associated with decreased OR on abnormal ALT (OR 0.3, 95\% CI 0.1-0.9). (3) Multiple linear and logistic regression also showed strong interactions of the VCM exposure to CYP2E1 as well as to the GST T1 genotype. These observations suggest that the two genotypes, CYP2E1 and GST T1, may play important roles in the biotransformation of VCM, the effect of which leads to liver damage.

Key words Vinyl chloride - Glutathione S-transferases • Cytochrome P-450 2E1 - Liver function

\section{Introduction}

Vinyl chloride monomer (VCM) has been associated with hepatotoxic effects in humans including liver fibrosis, cirrhosis, hepatomegaly, splenomegaly, portal hypertension, and angiosarcoma of the liver (Creech and Johnson 1974; Lilis et al. 1975; Smith and Crossley 1976; Simonato et al. 1991; Wang et al. 1991). Exposure to VCM may also cause abnormalities in one or more liver function tests, such as aspartate aminotransferase (AST), alanine aminotransferase (ALT) and gamma glutamyl transpeptidase (GGT; Makk et al. 1974; Lilis et al. 1975; Marsteller and Lelbach 1975; Ho et al. 1991; Du et al. 1995).

The liver is the primary target of VCM because it is believed that VCM is activated by cytochrome P450 2E1 (CYP2E1), an enzyme mainly existing in the liver (Guengerich et al. 1991; Koop 1992). CYP2E1 catalyses VCM oxidation into an epoxide intermediate, chloroethylene oxide (CEO), which is spontaneously rearranged into 2-chloroacetaldehyde (CAA). The electrophilic metabolites, CEO and CAA, considered to be the most important intermediates in the VCM carcinogenic 
process react with DNA bases to form adducts. The DNA-adducts are mutagenic in the bacterial system as well as in mammalian cells or covalently bind to proteins to impair cell function (Bolt 1986; Brandt-Rauf et al. 1995). These two metabolites may be further processed by glutathione S-transferases (GSTs; Bolt 1986; Easter and Von Burg 1994). The activities of these enzymes, GSTs and CYP2E1, are known to vary genetically among individuals. Thus, inter-individual differences in susceptibility to VCM exposure may be attributable to the differences in the activities of CYP2E1 and GSTs. Metabolism of VCM may proceed via different pathways at different concentrations (Easter and Von Burg 1994). The pathway described above mainly proceeds at high concentraion. At low concentration, VCM appears to be oxidized by alcohol dehydrogenase to form chloroethanol, CAA and chloroacetic acid. The latter two products may further conjugate with glutathione (GSH; Easter and Von Burg 1994). Therefore, the susceptibility of an individual to the induction of liver damage may depend on the exposure concentration of VCM. In other words, individuals with the same genetic trait exposed to different levels of VCM may exhibit different health effects.

The genetic variation in CYP2E1 is supported by recent identification of the restriction fragment length polymorphisms (RFLPs) of the CYP2E1 5'-flanking region detected by $P s t \mathrm{I}$ and $R s a \mathrm{I}$ digestion. The two restriction sites, PstI and $R s a \mathrm{I}$, are tightly linked and such genotype may affect the transcriptional regulation of CYP2E1 (Hayashi et al. 1991; Watanabe et al. 1994). The relationship has been reported between CYP2E1 genetic polymorphisms and susceptibility to lung cancer (Perrson et al. 1993), alcoholic liver disease (Maezawa et al. 1994; Tsutsumi et al. 1994; Chao et al. 1995), hepatocellular carcinoma ( $\mathrm{Yu}$ et al. 1995) and nasopharyngeal carcinoma (Hildesheim et al. 1995) respectively.

Concerning GSTs, the mammalian GST supergene family, composed of $\alpha, \pi, \mu$, and newly discovered $\theta$, catalyses the conjugation of GSH with electrophilic substrates. Some individuals carry a large deletion (null genotype) in the glutathione S-transferase $\theta$ (GST T1) and glutathione S-transferase $\mu$ (GST M1) gene, respectively. An individual without an intact GST M1 may have a higher risk of developing cancer or cytogenetic damage (Wiencke et al. 1990; Seidegard et al. 1986, 1990). The role of the newly discovered GST T1 remains controversial. An in vitro study shows that GST T1 deficiency may increase chromosome damage by ethylene oxide (Hallier et al. 1993) or by diepoxybutane (Norppa et al. 1995). On the other hand, there are some classes of agents (e.g. halomethanes) that are activated by conjugating with GSH to form mutagenic intermediates (Thier et al. 1993). Thus, different substrates metabolized by GST T1 may have different consequences (Hallier et al. 1993; Norppa et al. 1995; Thier et al. 1993; Nelson et al. 1995).

Several studies performed in the 1970s showed a higher prevalence of abnormal liver function in VCM exposed workers (Lilis et al. 1975; Makk et al. 1974; Marsteller and Lelbach 1975). However, other studies indicate that the liver function tests used are not sensitive enough to detect early VCM-induced liver damage (Williams et al. 1976; Sugita et al. 1986). Although AST, ALT and GGT have been proposed as indicators of liver damage, their specificity and sensitivity remain unknown. Ho et al. (1991) report that ALT is the earliest and most sensitive indicator of VCM-induced liver dysfunction followed by GGT. It is believed that ALT is more specific than AST as an indicator of liver damage since ALT is found primarily in the liver, whereas AST is also present in many other tissues including heart, skeletal muscle, kidney and brain (Podolsky and Isselbacher 1994). Because ALT is more sensitive and specific than AST or GGT, and more suitable for the screening of occupational toxic exposure (Redlich and Brodkin 1994; Widmann 1989), ALT was used as an indicator of liver damage in this study.

There may be interactions between the susceptible factors and chemical exposure. Hence, the magnitude and direction of associations between exposures and diseases may differ according to the extent of genetic susceptibilities (Vine and Mcfarland 1990). On the other hand, the effect of genetic susceptibilities may depend on the exposure concentrations when the metabolism of the chemical proceeds via different pathways at different concentrations. In this study, we attempted to determine whether or not there were interactions between the genotypes of CYP2E1, GST T1, and GST M1 and the VCM exposure in inducing liver damage.

\section{Materials and methods}

\section{Subjects}

Two hundred and eighty volunteers were recruited from five polyvinyl chloride (PVC) plants. Female workers $(n=13)$ were excluded from this study because of insufficient number. Those who were newly employed or changed workplace within 6 months $(n=13)$ were also excluded, on consideration that the time for the induction of liver damage from VCM exposure might not be sufficient (Marsteller and Lelbach 1975). Some data were missing from three workers, who were likewise excluded. Thus, a total of 251 male workers was employed for the final analysis. All workers received complete physical examinations and structured questionnaires including demographic data, smoking and drinking habits, and detailed occupational history. Questionnaires were administered by well-trained interviewers.

Subjects were divided into two exposure groups, high and low, according to the nature of their current job. The high-exposure group was defined as those individuals involved in unloading PVC or VCM, adding catalyst, tank cleaning, working in a control room, tank stripping, and being a foreman; the low-exposure group were those individuals involved in the drying operation, laboratory testing, managing industrial hygiene, machine maintenance, PVC storage, gatehouse keeping, administration and car driving. Exposure assessment performed 1 year before this study showed that the $8 \mathrm{~h}$ time-weighted average (TWA) of VCM in the low-exposure group was always $\leq 1 \mathrm{ppm}$, while the TWA of VCM in the highexposure group ranged from 1 to $5 \mathrm{ppm}$; occasionally concentrations up to $40 \mathrm{ppm}$ were found in certain jobs including unloading of PVC, adding of catalyst and tank cleaning. 
Samples

Ten millilitres of venous blood were drawn into heparinized tubes (Vacutainer) and stored at $4{ }^{\circ} \mathrm{C}$. The whole blood was separated into plasma, buffy coat, and red blood cells by centrifugation within $18 \mathrm{~h}$ of obtaining the blood, then stored in a $-70{ }^{\circ} \mathrm{C}$ freezer. Genomic DNA was extracted and purified from buffy coat as previously described (Hsieh et al. 1996).

\section{Measurement of ALT}

ALT was analysed with a Hitachi 7050 autoanalyser. Enzyme immunoassay (Austria-II, Abbott Lab., Chicago, Il., USA) was used to determine the presence or absence of the serum hepatitis B virus surface antigen ( $\mathrm{HBs} \mathrm{Ag}$ ) and anti-hepatitis $\mathrm{C}$ virus antibody (anti$\mathrm{HCV} \mathrm{Ab).} \mathrm{All} \mathrm{these} \mathrm{tests} \mathrm{were} \mathrm{performed} \mathrm{in} \mathrm{the} \mathrm{central} \mathrm{laboratory}$ of the National Taiwan University Hospital; the cut-off value of $31 \mathrm{IU} / 1$ adopted here for the abnormality of the ALT was that used by the central laboratory.

\section{Genotyping of the GST T1 and GST M1 gene}

A simple assay based on polymerase chain reaction (PCR) technology was available to determine the presence or absence of GST T1 (Pemble et al. 1994) and GST M1 (Comstock et al. 1990). Briefly, PCR was performed in a $25 \mu \mathrm{l}$ mixture containing the buffer supplied by Promega (Madison, Wis., USA), $250 \mathrm{ng}$ of genomic DNA, Taq DNA polymerase (1 U), four bases (dNTP), and $200 \mathrm{ng}$ of each of the primers for GST T1 (5'-TTCCTTACTGGTCCTCACATCTC-3' and 5'-CACCGGATCATGGCCAGCA-3'), GST M1 (5'-TGCCCTACTTGATTGATGGG-3' and $5^{\prime}$-CTGGATTGTAGCAGATCATGC-3') and the internal control, $\beta$-globin (5'-CACAACTGTGTTCACTAGC-3' and 5'-CAACTTCATCCACGTTCACC-3'). The running conditions were: 30 cycles at $95{ }^{\circ} \mathrm{C}$ for $30 \mathrm{~s}, 6{ }^{\circ} \mathrm{C}$ for $15 \mathrm{~s}$, and $72{ }^{\circ} \mathrm{C}$ for $1 \mathrm{~min}$. The PCR product was electrophoresed in $6 \%$ polyacrylamide gel, stained with ethidium bromide and photographed under UV light. Individuals without an intact GST T1 or GST M1 gene showed no amplification of the $480 \mathrm{bp}$ GST T1 fragment or the $273 \mathrm{bp}$ GST M1 fragment and a positive internal control, the $100 \mathrm{bp} \beta$-globin fragment (Fig. 1).

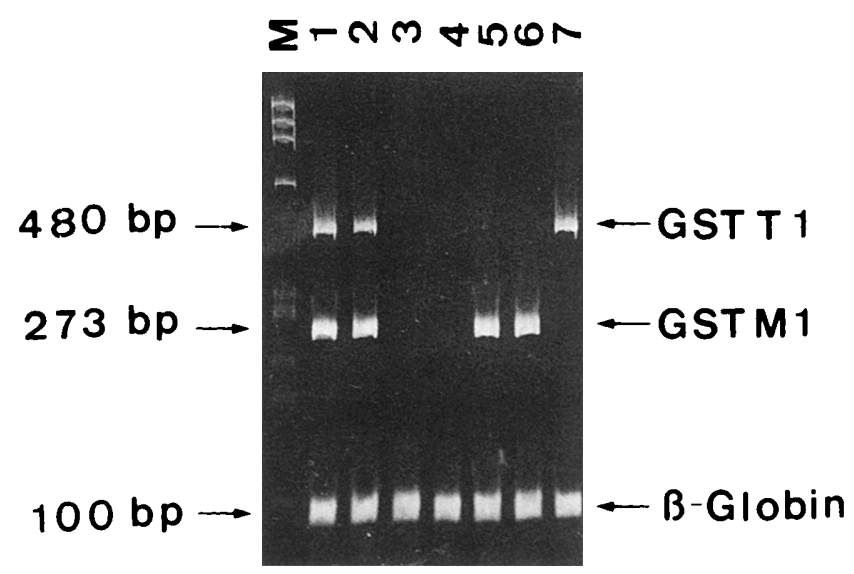

Fig. 1 Representative results of polymerase chain reaction (PCR) of the GST M1 and GST T1 gene from PVC workers. Genomic DNAs were amplified using PCR, and the products electrophoresed in polyacrylamide gels, and stained with ethidium bromide. The 480 and $273 \mathrm{bp}$ DNA fragments correspond to GST T1 and GST M1, respectively, while the $100 \mathrm{bp}$ DNA fragment corresponds to the $\beta$ globin gene as internal control (PVC Polyvinyl chloride, GST glutathione S-transferase)

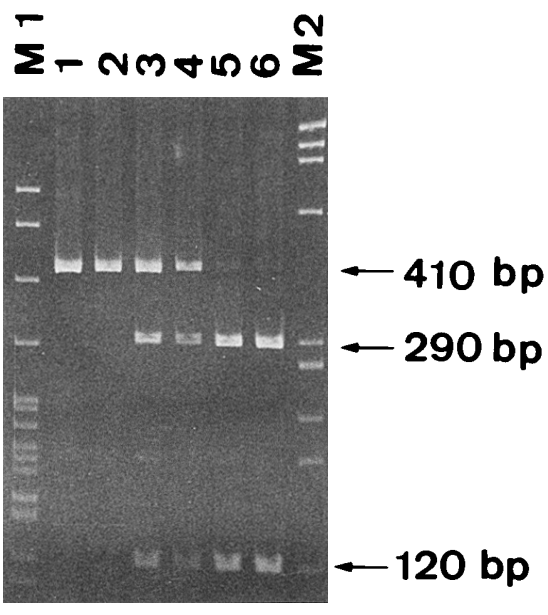

Fig. 2 Representative results of PCR-RFLP analysis of the CYP2E1 gene from PVC workers. Genomic DNAs were amplified using PCR, and the products digested with Pst $\mathrm{I}$, electrophoresed in polyacrylamide gels, and stained with ethidium bromide. The 410 bp DNA fragment corresponds to the $\mathrm{cl}$ allele which does not have a PstI site, while the paired fragments of 290 and $120 \mathrm{bp}$, correspond to the $\mathrm{c} 2$ allele containing the PstI site (RFLP Restriction fragment length polymorphism)

Determination of PstI fragment polymorphism of the CYP2E1 gene

To determine the CYP2E1 fragment polymorphism, genomic DNA was amplified in a $20 \mu \mathrm{l}$ mixture containing $500 \mathrm{ng}$ of genomic DNA, and $160 \mathrm{ng}$ of each primer (5'-CAGTCGAGTCTACATTGTC-3' and 5'-TTCATTCTGTCTTCTAACTG-3') flanking the polymorphic PstI site, for 30 cycles (Hayashi et al. 1991) using the running conditions: $95^{\circ} \mathrm{C}$ for $30 \mathrm{~s}, 57^{\circ} \mathrm{C}$ for $15 \mathrm{~s}$, and $72{ }^{\circ} \mathrm{C}$ for 1 min. The PCR product was digested overnight with Pst I (7.5 units) at $37{ }^{\circ} \mathrm{C}$, electrophoresed in $6 \%$ polyacrylamide gels, stained with ethidium bromide and photographed under UV light. The PCR product of CYP2E1 digested with restriction enzyme PstI showed three genotypes of CYP2E1: type c1c1 was not digested by Pst I and showed only one band of $410 \mathrm{bp}$; heterozygous type c1c2 showed three bands of 410, 290 and $120 \mathrm{bp}$; and type c2c2 showed 2 bands of 290 and 120 bp by polyacrylamide gel electrophoresis (Fig. 2).

\section{Statistical analysis}

Statistical Analysis System (SAS) version 6.10 and EGRET (Epidemiologic Graphic, Estimation, and Testing package) were used for the statistical analysis. $\chi^{2}$-test was used to compare the difference of basic characteristics between the high- and low-VCM exposure groups. To assess the effect of potential risk factors on liver function, $\mathrm{HBs} \mathrm{Ag}$, anti-HCV Ab, habitual alcohol drinking (habitual drinking of at least once a week), age, employment duration, body mass index (BMI), VCM exposure and the genotypes GST T1, GST M1, and CYP2E1 were included in the univariate analyses. Stratified analyses were used to explore the correlation between the alteration of liver function and the genotypes, CYP2E1, GST T1 and GST M1, among the workers exposed to different levels of VCM. Subsequently, a multiple logistic regression model was used to estimate the adjusted odds ratio (OR) of the above risk factors and the effect on abnormal liver function of interactions between the genotypes GST T1, GST M1, and CYP2E1 and alcohol drinking (i.e. habitual alcohol drinking $\times$ GST T1, GST M1 or CYP2E1) or VCM exposure, (i.e. VCM exposure $\times$ GST T1, GST M1 or CYP2E1). The stepwise and backward procedures were used to select the best model. Similar procedures were also used to select the best multiple linear regression model. 


\section{Results}

The basic characteristics of 251 male workers are shown in Table 1. The high-VCM exposure group seemed to have a higher prevalence of habitual alcohol drinking than the low-VCM exposure group $\left(\chi^{2}=7.426\right.$, $P<0.01)$; otherwise all the other characteristics of age, BMI, employment duration, and prevalence of positive $\mathrm{HBs} \mathrm{Ag}$ and anti-HCV Ab, were not statistically different between these two exposure groups. Because the number of positive anti-HCV Ab was small, the data on $\mathrm{HBs} \mathrm{Ag}$ and anti-HCV Ab were combined and used as the indicator of hepatitis virus infection. When either the $\mathrm{HBs} \mathrm{Ag}$ or anti-HCV Ab test was positive, the person was scored as positive for virus infection. The genotypic distribution of GST T1, GST M1 and CYP2E1 among the two VCM exposure groups was similar. The total frequency of the null-genotype of GST T1 and GST M1 was 47.4 and $60.6 \%$, respectively. The frequency of the

Table 1 Basic characteristics of the polyvinyl chloride (PVC) workers stratified by vinyl chloride monomer (VCM) exposure (HBs Ag Serum hepatitis B virus surface antigen, anti-HCV $A b$ anti-hepatitis $\mathrm{C}$ virus antibody, $G S T$ glutathione S-transferase)

\begin{tabular}{|c|c|c|c|}
\hline & \multicolumn{3}{|c|}{ VCM exposure } \\
\hline & $\begin{array}{l}\text { Low } \\
(n=111) \\
\mathrm{n}(\%)\end{array}$ & $\begin{array}{l}\text { High } \\
(n=140) \\
\mathrm{n}(\%)\end{array}$ & $\begin{array}{l}\text { Total } \\
(n=251) \\
\mathrm{n}(\%)\end{array}$ \\
\hline \multicolumn{4}{|l|}{ Age } \\
\hline$<40$ years & $43(38.7)$ & $70(50)$ & $113(45.0)$ \\
\hline$\geq 40$ years & $68(61.3)$ & $70(50)$ & $138(55.0)$ \\
\hline \multicolumn{4}{|c|}{ Employment duration } \\
\hline$<15$ years & $46(41.4)$ & $72(51.4)$ & $118(47.0)$ \\
\hline$\geq 15$ years & $65(58.6)$ & $68(48.6)$ & $133(53.0)$ \\
\hline \multicolumn{4}{|c|}{ Body mass index } \\
\hline$<25 \mathrm{~kg} / \mathrm{m}^{2}$ & $90(81.1)$ & $103(73.6)$ & $193(76.9)$ \\
\hline$\geq 25 \mathrm{~kg} / \mathrm{m}^{2}$ & $21(18.9)$ & $37(26.4)$ & $58(23.1)$ \\
\hline \multicolumn{4}{|l|}{ Drinking ${ }^{a}$} \\
\hline No & $104(93.7)$ & $115(82.1)$ & $219(87.3)$ \\
\hline Yes & $7(6.3)^{*}$ & $25(17.9)^{*}$ & $32(12.7)$ \\
\hline \multicolumn{4}{|l|}{$\mathrm{HBs} \mathrm{Ag}$} \\
\hline Negative & $91(82.0)$ & $110(78.6)$ & $201(80.1)$ \\
\hline Positive & $20(18.0)$ & $30(21.4)$ & $50(19.9)$ \\
\hline \multicolumn{4}{|c|}{ Anti-HCV Ab } \\
\hline Negative & $109(98.2)$ & $136(97.1)$ & $245(97.6)$ \\
\hline Positive & $2(1.8)$ & $4(2.9)$ & $6(2.4)$ \\
\hline \multicolumn{4}{|c|}{ Virus infection $^{\mathrm{b}}$} \\
\hline Negative & $89(80.2)$ & $108(77.1)$ & $197(78.5)$ \\
\hline Positive & $22(19.8)$ & $32(22.9)$ & $54(21.5)$ \\
\hline \multicolumn{4}{|c|}{ GST T1 genotype } \\
\hline Null & $58(52.3)$ & $61(43.6)$ & $119(47.4)$ \\
\hline Positive & $53(47.7)$ & $79(56.4)$ & $132(52.6)$ \\
\hline \multicolumn{4}{|c|}{ GST M1 genotype } \\
\hline Null & $70(63.1)$ & $82(58.6)$ & $152(60.6)$ \\
\hline Positive & $41(36.9)$ & $58(41.4)$ & $99(39.4)$ \\
\hline \multicolumn{4}{|c|}{ CYP2E1 genotype } \\
\hline clc1 & $61(55.0)$ & $78(55.7)$ & $139(55.4)$ \\
\hline $\mathrm{c} 1 \mathrm{c} 2$ & $44(39.6)$ & $55(39.3)$ & $99(39.4)$ \\
\hline $\mathrm{c} 2 \mathrm{c} 2$ & $6(5.4)$ & $7(5.0)$ & $13(5.2)$ \\
\hline
\end{tabular}

$* \chi^{2}=7.426, P<0.01$

a Drinking, Habitual alcohol drinking $\geq$ once a week

${ }^{\mathrm{b}}$ Virus infection positive, $\mathrm{HBs} \mathrm{Ag}$ positive or anti-HCV Ab positive
Table 2 Odds ratio (OR; with $95 \%$ confidence interval) for abnormal ALT in PVC workers (ALT Alanine aminotransferase)

\begin{tabular}{|c|c|c|c|}
\hline & $\begin{array}{l}\text { Normal } \\
n(\%)\end{array}$ & $\begin{array}{l}\text { Abnormal } \\
n(\%)\end{array}$ & OR( $(95 \% \mathrm{CI})$ \\
\hline \multicolumn{4}{|c|}{ VCM exposure } \\
\hline Low & $92(43.2)$ & $19(50.0)$ & 1 \\
\hline High & $121(56.8)$ & $19(50.0)$ & $0.8(0.4,1.62)$ \\
\hline \multicolumn{4}{|c|}{ GST T1genotype } \\
\hline Null & $101(47.4)$ & $18(47.4)$ & 1 \\
\hline Positive & $112(52.6)$ & $20(52.6)$ & $1.0(0.5,2.1)$ \\
\hline \multicolumn{4}{|c|}{ GST M1genotype } \\
\hline Null & $129(60.6)$ & $23(60.5)$ & 1 \\
\hline Positive & $84(39.4)$ & $15(39.5)$ & $1.0(0.5,2.1)$ \\
\hline \multicolumn{4}{|c|}{ CYP2E1genotype } \\
\hline $\mathrm{clcl} / \mathrm{clc} 2$ & $204(95.8)$ & $34(89.5)$ & 1 \\
\hline $\mathrm{c} 2 \mathrm{c} 2$ & $9(4.2)$ & $4(10.5)$ & $2.7(0.6,10.2)^{*}$ \\
\hline \multicolumn{4}{|l|}{ Virus infection } \\
\hline Negative & $176(82.6)$ & $21(55.3)$ & 1 \\
\hline Positive & $37(17.4)$ & $17(44.7)$ & $3.8(1.7,8.5)^{* *}$ \\
\hline \multicolumn{4}{|l|}{ Drinking ${ }^{\mathrm{a}}$} \\
\hline Negative & $187(87.8)$ & $32(84.2)$ & 1 \\
\hline Positive & $26(12.2)$ & $6(15.8)$ & $1.4(0.4,3.7)$ \\
\hline \multicolumn{4}{|c|}{ Body mass index } \\
\hline$<25 \mathrm{~kg} / \mathrm{m}^{2}$ & $172(80.8)$ & $21(55.3)$ & 1 \\
\hline$\geq 25 \mathrm{~kg} / \mathrm{m}^{2}$ & $41(19.2)$ & $17(44.7)$ & $3.4(1.5,7.4)^{* *}$ \\
\hline \multicolumn{4}{|c|}{ Employment duration } \\
\hline$<15$ years & $100(46.9)$ & $18(47.4)$ & 1 \\
\hline$\geq 5$ years & $113(53.1)$ & $20(52.6)$ & $1.0(0.5,2.1)$ \\
\hline
\end{tabular}

* $P=0.12$; ** $P<0.01$; other $P$-value $>0.1$

${ }^{a}$ Drinking, Habitual alcohol drinking $\geq$ once a week

c1c1, c1c2 and c2c2 genotypes of CYP2E1 was 55.4, 39.4 and $5.2 \%$, respectively.

The results of univariate analysis are shown in Table 2. Virus infection [OR (odds ratio) 3.8, $P<0.01$, 95\% CI 1.7-8.5], and BMI (OR 3.4, $P<0.01,95 \%$ CI 1.5-7.4) were significantly associated with abnormal ALT. Individuals with CYP2E1 c2c2 genotype had a higher frequency of abnormal ALT but without statistical significance (OR 2.7, $P=0.12,95 \%$ CI 0.6-10.2). The factors VCM exposure, the genotypes of GST T1 and GST M1, habitual alcohol drinking, and employment duration, were not associated with abnormal ALT in univariate analyses.

Because the metabolism of VCM may differ at different concentrations, the prevalence of abnormal ALT associated with the genotypes of these metabolic enzymes may be affected by the levels of VCM exposure. In the low-VCM exposure group, the frequency of the GST T1 positive genotype was significantly higher in workers with abnormal ALT (OR 3.8, 95\% CI 1.2-14.5) but the CYP2E1 genotype was not associated with abnormal ALT. In the high-VCM exposure group, the frequency of the GST T1 positive genotype was significantly lower in workers with abnormal ALT (OR 0.3, 95\% CI 0.1-0.9) and the c2c2 genotype of CYP2E1 was associated with increased OR on abnormal ALT (OR $5.4,95 \%$ CI $0.7-35.1$ ). No association was found between the GST M1 genotype and abnormal ALT whether the VCM exposure was low or high. A significant interaction between the GST T1 genotype and 
Table 3 OR (with 95\% CI) of abnormal ALT in relation to the GST T1, GST M1 and CYP2E1 genotypes

\begin{tabular}{|c|c|c|c|c|c|c|}
\hline & \multicolumn{6}{|c|}{ VCM exposure } \\
\hline & \multicolumn{3}{|l|}{ Low } & \multicolumn{3}{|l|}{ High } \\
\hline & $\begin{array}{l}\text { Normal } \\
n\end{array}$ & $\begin{array}{l}\text { Abnormal } \\
n\end{array}$ & OR $(95 \% \mathrm{CI})$ & $\begin{array}{l}\text { Normal } \\
n\end{array}$ & $\begin{array}{l}\text { Abnormal } \\
n\end{array}$ & OR $(95 \% \mathrm{CI})$ \\
\hline \multicolumn{7}{|c|}{ GST T1 genotype } \\
\hline Null & 53 & 5 & 1 & 48 & 13 & 1 \\
\hline \multirow[t]{2}{*}{ Positive } & 39 & 14 & $3.8(1.2,14.5)^{* *}$ & 73 & 6 & $0.3(0.1,0.9)^{* *}$ \\
\hline & \multicolumn{6}{|c|}{ Maentel-Haenszel test for homogeneity, $P<0.001$} \\
\hline \multicolumn{7}{|c|}{ GST M1 genotype } \\
\hline Null & 58 & 12 & 1 & 71 & 11 & 1 \\
\hline \multirow[t]{2}{*}{ Positive } & 34 & 7 & $1.0(0.3,3.1)$ & 50 & 8 & $1.0(0.3,3.1)$ \\
\hline & \multicolumn{6}{|c|}{ Maentel-Haenszel test for homogeneity, $P=0.96$} \\
\hline \multirow{4}{*}{$\begin{array}{l}\text { CYP2E1 ger } \\
\text { c1c1/c1c2 } \\
\text { c2c2 }\end{array}$} & & & & & & \\
\hline & 87 & 18 & 1 & 117 & 16 & 1 \\
\hline & 5 & 1 & $1.0(0.0,9.4)$ & 4 & 3 & $5.4(0.7,35.1)^{*}$ \\
\hline & \multicolumn{6}{|c|}{ Maentel-Haenszel test for homogeneity, $P=0.19$} \\
\hline
\end{tabular}

$* P=0.053 ; * * 0.01<P<0.05$; other $P$-value $>0.1$

VCM exposure was indicated based on the analysis using a multiplicative model $(P<0.001$, Maentel-Haenszel test for homogeneity). Although the OR for the c2c2 genotype was different in the low or high VCM exposure groups, a statistical test for the interaction between the CYP2E1 genotype and VCM exposure indicated non-significance $(P=0.19$, Maentel-Haenszel test for homogeneity; Table 3)

The data of Table 4 give the best fitted multiple logistic and linear regression models. In the multiple logistic regression model, virus infection (OR 6.4, $P<0.01,95 \%$ CI $2.7-15.3)$, and BMI of $\geq 25 \mathrm{~kg} / \mathrm{m}^{2}$
(OR 5.7, $P<0.01,95 \%$ CI 2.4-13.7) were significantly associated with increased OR on abnormal ALT. Interactions between VCM exposure and the genotypes of GST T1 and CYP2E1 could be seen. The effects of the GST T1 or CYP2E1 genotypes on inducing liver damage differed with different levels of VCM exposure; therefore, the odds ratio should be discussed separately on each category. Compared to individuals with low VCM exposure and null GST T1, the OR for individuals with combined GST T1 positive and low VCM exposure on abnormal ALT was 7.1 times the null genotype at low VCM (OR 7.1, 95\% CI 2.1-24.1, $P<0.01$ ), while the
Table 4 Multiple linear and logistic regression model for ALT in PVC workers, $n=251$ (BMI Body mass index)

\begin{tabular}{|c|c|c|}
\hline & Logistic regression & Linear regression \\
\hline & OR $(95 \% \mathrm{CI})$ & $\beta(95 \% \mathrm{CI})$ \\
\hline \multicolumn{3}{|l|}{ Virus infection } \\
\hline Positive vs negative & $6.4(2.7,15.3)^{ \pm}$ & $15.8(11.2,20.4)^{*}$ \\
\hline \multicolumn{3}{|l|}{ Drinking $^{\mathrm{a}}$} \\
\hline Yes vs No & - & $10.6(4.8,16.3)^{\ddagger}$ \\
\hline \multicolumn{3}{|l|}{$\operatorname{BMI}\left(\mathrm{kg} / \mathrm{m}^{2}\right)$} \\
\hline$\geq 25$ vs $<25$ & $5.7(2.4,13.7)^{*}$ & $7.2(2.7,11.7)^{\ddagger}$ \\
\hline \multicolumn{3}{|l|}{ VCM exposure } \\
\hline High vs low & $2.7(0.8,9.0)$ & $1.2(-4.3,6.8)$ \\
\hline \multicolumn{3}{|l|}{ GST T1 genotype } \\
\hline Positive vs null & $7.1(2.1,24.6)^{*}$ & $4.9(-0.8,10.6)^{*}$ \\
\hline $\begin{array}{l}\text { Interactions between VCM } \\
\text { exposure and GST T1 genotype }\end{array}$ & $0.03(0.004,0.2)^{*}$ & $-10.7(-18.3,-3.1)^{1}$ \\
\hline \multicolumn{3}{|l|}{ CYP2E1 $\cdot$ genotype } \\
\hline $\mathrm{c} 2 \mathrm{c} 2$ vs $\mathrm{c} 1 \mathrm{c} 1 / \mathrm{clc} 2$ & $0.5(0.04,5.7)$ & $-5.9(-18.5,6.7)$ \\
\hline $\begin{array}{l}\text { Interactions between VCM exposure } \\
\text { and CYP2E1 genotype }\end{array}$ & $17.2(0.8,350.0)^{* *}$ & $18.2(1.1,35.3)^{* * *}$ \\
\hline \multicolumn{3}{|c|}{$\begin{array}{l}{ }^{\mathrm{b}} \text { Interactions between VCM exposure and GST T1 genotype were identified in the logistic regression } \\
\text { (see the text) } \\
\text { c Interactions between VCM exposure and CYP2E1 genotype were identified in the logistic regression } \\
\text { (see the text) }\end{array}$} \\
\hline
\end{tabular}


OR for individuals with combined GST T1 positive and high VCM exposure differed by only 0.6 times (OR of $2.7 \times 7.1 \times 0.03 \simeq 0.6,95 \%$ CI $0.1-2.2, P>0.1)$. The OR of the CYP2E1 c2c2 genotype on abnormal ALT was highly significant in the high VCM exposure group $(\mathrm{OR}$ of $2.7 \times 0.5 \times 17.2 \simeq 23.3, P<0.01,95 \%$ CI $3.1-$ 176.1), but was insignificant in the low VCM exposure group (OR 0.5, $P>0.1,95 \%$ CI $0.0-5.7$ ). Similar interactions were also observed with the linear regression model (Table 4).

\section{Discussion}

In this study population, the frequency of the CYP2E1 c2 allele of $24.9 \%$, is comparable to that shown in the previous study for Taiwanese (Stephens et al. 1994; Chao et al. 1995). The frequency of the GST M1 null genotype in our present study group $(60.6 \%)$ is similar to that in the control group of a hepatocellular carcinoma study in Taiwan (63.3\%; Yu et al. 1995). The frequency of GST T1 in Taiwan, however, has not been reported. The frequency of the GST T1 null genotype in China is $64.4 \%$ (Nelson et al. 1995) differing from our result of $47.4 \%$.

Virus infection and BMI of $\geq 25 \mathrm{~kg} / \mathrm{m}^{2}$ are shown to be the major risk factors for abnormal ALT in this study. Habitual alcohol drinking is weakly associated with abnormal ALT because alcohol may selectively inhibit ALT activity (Redlich and Brodkin 1994). In stratified analyses, the positive GST T1 shows a different effect on inducing abnormal ALT at different levels of VCM exposure, and CYP2E1 c2c2 is shown to be associated with abnormal ALT only in the high-VCM exposure group. Similar interactions between the VCM exposure and the genotypes of GST T1 and CYP2E1 are seen when analysed with the multiple logistic as well as the linear regression model.

In the present study, the VCM exposure and the genotypes of GST T1 and CYP2E1 are shown to interact with each other to affect ALT. Since these variables do not operate independently, the discussion of the individual effect of VCM exposure and the genotypes of GST T1 and CYP2E1 on the induction of liver damage should be avoided. The OR for individuals with positive GST T1 at high VCM exposure on abnormal ALT is 0.6 times the individuals with null GST T1 at low VCM exposure. However, the OR for individuals with positive GST T1 at low VCM exposure on abnormal ALT was 7.1 times higher than individuals with null GST T1 at low VCM exposure. Thus, the effect of GST T1 on inducing liver damage differed with different levels of $\mathrm{VCM}$ exposure.

The role of newly discovered GST T1 remains controversial. Different substrates metabolized by GST T1 may have different effects (Hallier et al. 1993; Norppa et al. 1995; Thier et al. 1993; Nelson et al. 1995). The metabolic pathway for VCM may depend on its concentration. At a low concentration, VCM may be pre- dominantly metabolized by alcohol dehydrogenase to form 2-chloroethanol, CAA and 2-chloroacetic acid. At a high concentration, it may be oxidized to form CEO by cytochrome P-450s and/or spontaneously rearranged to form CAA (Easter and Von Burg 1994). The above alkylating metabolites including CAA and CEO may be further metabolized by the GSTs (Bolt 1986; Easter and Von Burg 1994). Thus, individuals with positive GST T1 exposed to different levels of VCM may have different effects on liver function due to different phase I metabolites formed. Furthermore, VCM may be directly metabolized by GSTs to conjugate with GSH (Hefner et al. 1975) and these GSH-conjugates may have mutagenic activity, such as ethylene dibromide conjugated with GSH to form alkylating intermediates (Thier et al. 1993). The GST T1 positive genotype is significantly associated with increased OR on abnormal ALT only at low VCM exposure as observed in this study. Therefore, VCM may be mainly metabolized directly by GST T1 at low concentration to form more toxic intermediates.

The transcriptional activity of the CYP2E1 c2c2 genotype has been shown to be about 10 times the activity of the clc1 genotype (Hayashi et al. 1991); however, the level of the final protein product has not been verified. VCM is primarily metabolized by CYP2E1 at high concentration, in partial explanation of why the significant association of the CYP2E1 c2c2 genotype with increased OR on abnormal ALT only at high VCM exposure.

The above observation, therefore, indicates that GST T1 and CYP2E1 may play important roles in the biotransformation of VCM; hence, at low concentration, VCM is metabolized by GST T1 or alcohol dehydrogenase and at high concentration, by CYP 2E1. Accordingly, the effect of these metabolic enzymes on the induction of abnormal ALT is different at different levels of VCM exposure. The association between abnormal ALT and the polymorphism of alcohol dehydrogenase among these PVC workers should be investigated further to elucidate the roles of metabolic traits on the toxic effects of VCM.

Acknowledgements We thank Dr Chung-Li Du for technical assistance and Dr J.T. Ou for helpful discussions. This study was supported by NSC grant NSC86-2314-B002-332.

\section{References}

Bolt HM (1986) Metabolic activation of vinyl chloride formation of nucleic acid adducts and relevance to carcinogenesis. IARC Sci Publ 70: 261-268

Brandt-Rauf PW, Marion MJ. DeVivo I (1995) Mutant p21 protein as a biomarker of chemical carcinogenesis in humans. In: Mendelsohn ML, Peeters JP, Normandy MJ (eds) Biomarkers and occupational health - progress and perspectives. Joseph Henry, Washington DC, pp 163-173

Chao YC, Young TH, Chang WK, Tang HS, Hsu CT (1995) An investigation of whether polymorphisms of cytochrome P450 $2 \mathrm{E} 1$ are genetic markers of susceptibility to alcoholic end-stage organ damage in a Chinese population. Hepatology 22: 14091414 
Comstock KE, Sanderson BJS, Claflin G, Henner WD (1990) GST1 gene deletion determined by polymerase chain reaction. Nucleic Acids Res 18: 3670

Creech JL, Johnson MN (1974) Angiosarcoma of liver in the manufacture of polyvinyl chloride. J Occup Med 16: 150-151

Du CL, Kuo ML, Chang HL, Sheu TJ, Wang JD (1995) Changes in lymphocyte single strand breakage and liver function of workers exposed to vinyl chloride monomer. Toxicol Lett 77: 379-385

Easter MD, Von Burg R (1994) Toxicology update - vinyl chloride. J Appl Toxicol 14: 301-307

Guengerich FP, Kim DH, Iwasaki M (1991) Role of human cytochrome P-450 IIE1 in the oxidation of many low molecular weight cancer suspects. Chem Res Toxicol 4: 168-179

Hallier E, Langhof T, Dannappel D, Leutbecher M, Schroder K, Goergens HW, Muller A, Bolt HM (1993) Polymorphism of glutathione conjugation of methyl bromide, ethylene oxide and dichloromethane in human blood: influence on the induction of sister chromatid exchanges (SCE) in lymphocytes. Arch Toxicol 67: $173-178$

Hayashi S, Watanabe J, Kawajiri K (1991) Genetic polymorphisms in the $5^{\prime}$-flanking region change transcriptional regulation of the human cytochrome P450IIE1 gene. J Biochem 110: 559-565

Hefner RE, Watanabe PG Jr, Gehring PJ (1975) Preliminary studies of the fate of inhaled vinyl chloride monomer in rats. Ann NY Acad Sci 246: 135-148

Hildesheim A, Chen CJ, Caporaso NE, Cheng YJ, Hoover RN, Hsu MM, Levine PH, Chen IH, Chen JY, Yang CS, Daly AK, Idle JR (1995) Cytochrome P450 2E1 genetic polymorphisms and risk of nasopharyngeal carcinoma: results from a casecontrol study conducted in Taiwan. Cancer Epidemiol Biomarkers Prev 4: 607-610

Ho SF, Phoon WH, Gan SL, Chan YK (1991) Persistent liver dysfunction among workers at a vinyl chloride monomer polymerization plant. J Soc Occup Med 41: 10-16

Hsieh LL, Huang R, Yu MW, Chen CJ, Liaw YF (1996) L-myc, GST M1 genetic polymorphism and hepatocellular carcinoma risk among chronic hepatitis B carriers. Cancer Lett 103: 171176

Koop DR (1992) Oxidative and reductive metabolism by cytochrome P450 2E1. FASEB J 6: 724-730

Lilis R, Anderson H, Nicholson WJ, Daum S, Fischbein AS, Selikoff IJ (1975) Prevalence of disease among vinyl chloride and polyvinyl chloride workers. Ann NY Acad Sci 246: 22-41

Maezawa Y, Yamauchi M, Toda G (1994) Association between restriction fragment length polymorphism of the human cytochrome P450IIE1 gene and susceptibility to alcoholic liver cirrhosis. Am J Gastroenterol 89: 561-565

Makk L, Creech JL, Whelan JG, Johnson MN (1974) Liver damage and angiosarcoma in vinyl chloride workers - a systemic detection program. JAm Med Assoc 230: 64-68

Marsteller HJ, Lelbach WK (1975) Unusual splenomegalic liver disease as evidenced by peritoneoscopy and guided liver biopsy among polyvinyl chloride production workers. Ann NY Acad Sci 246: 95-134

Nelson HH, Wiencke JK, Christiani DC, Cheng TJ, Zuo ZF, Schwartz BS, Lee BK, Spitz MR, Wang M, Xu XP, Kelsey KT (1995) Ethnic differences in the prevalence of the homozygous deleted genotype of glutathione S-transferase theta. Carcinogenesis 16: 1243-1245

Norppa H, Hirvonen A, Jarventaus H, Uuskula M, Tasa G, Ojajarvi A, Sorsa M (1995) Role of GSTT1 and GSTM1 genotypes in determining individual sensitivity to sister chromatid exchange induction by diepoxybutane in cultured human lymphocytes. Carcinogenesis 16: 1261-1264

Pemble S, Schroeder KR, Spencer SR, Meyer DJ, Hallier E, Bolt HM, Ketterer B, Taylor JB (1994) Human glutathione S- transferase theta (GSTT1): cDNA cloning and the characterization of a genetic polymorphism. Biochem J 300: 271-276

Perrson I, Johansson I, Bergling H, Dahl ML, Seidegard J, Rylander R, Rannug A, Hogberg J, Sundberg MI (1993) Genetic polymorphism of cytochrome P4502E1 in a Swedish population - relationship to incidence of lung cancer. FEBS Lett 319: 207-211

Podolsky DK, Isselbacher KJ (1994) Diagnostic tests in liver disease. In: Wilson JD, Braunwald E, Isslebacher KJ, Petersdorf RG, Martin JB, Fauci AS, Root RK (eds) Harrison's principle of internal medicine. McGraw-Hill, New York,

Redlich C, Brodkin CA (1994) Gastrointestinal disorders - liver diseases. In: Rosenstock L, Cullen M (eds) Textbooks of clinical environmental and occupational medicine. W.B. Saunders, Philadelphia, pp 423-436

Seidegard J, Pero RW, Miller DG, Beattie EJ (1986) A glutathione transferase in human leukocytes as a marker for the susceptibility to lung cancer. Carcinogenesis 7: 751-753

Seidegard J, Pero RW, Markowitz MM, Roush G, Miller DG, Beattie EJ (1990) Isoenzyme(s) of glutathione (class Mu) as a marker for the susceptibility to lung cancer: a follow up study. Carcinogenesis 11: 33-36

Simonato L, L'abbe KA, Anderson A, Belli S, Comba P, Engholm G, Ferro G, Hagmar L, Langard S, Lundberg I, Pirastu R, Thomas P, Winkelmann R, Saracci R (1991) A collaborative study of cancer incidence and mortality among vinyl chloride workers. Scand J Work Environ Health 17: 159-169

Smith PM, Crossley IR (1976) Portal hypertension in vinyl-chloride production workers. Lancet 2: 602-604

Stephens EA, Taylor JA, Kaplan N, Yang CH, Hsieh LL, Lucier GW, Bell DA (1994) Ethnic variation in the CYP2E1 gene: polymorphism analysis of 695 African-Americans, EuropeanAmericans and Taiwanese. Pharmacogenetics 4: 185-192

Sugita M, Masuda Y, Tsuchiya K (1986) Early detection and signs of hepatoangiosarcoma among vinyl chloride workers. Am J Ind Med 10: 411-417

Thier R, Taylor JB, Pemble SE, Humphreys WG, Persmark M, Ketterer B, Guengerich FP (1993) Expression of mammalian glutathione S-transferase 5-5 in Salmonella typhimurium TA 1535 leads to base-pair mutations upon exposure to dihalomethanes. Proc Natl Acad Sci USA 90: 8576-8580

Tsutsumi M, Takada A, Wang JS (1994) Genetic polymorphisms of cytochrome P4502E1 related to the development of alcoholic liver disease. Gastroenterology 107: 1430-1435

Vine MF, Mcfarland LT (1990) Markers of susceptibility. In: Hulka BS, Wilcosky TC, Griffith JD (eds) Biological markers in epidemiology. Oxford University Press, New York, pp 196-213

Wang O, Whorton MD, Foliart SE, Ragland D (1991) An industry-wide epidemiologic study of vinyl chloride workers, 19421982. Am J Ind Med 20: 317-334

Watanabe J, Hayashi S, Kawajiri K (1994) Different regulation and expression of the human CYP2E1 gene due to the RsaI polymorphism in the 5'-flanking region. J Biochem 116: 321-326

Widmann FK (1989) Clinical interpretation of laboratory tests. F.A. Davis, Philadelphia

Wiencke JK, Kelsey KT, Lamela RA, Toscano WA (1990) Human glutathione S-transferase deficiency as a marker of susceptibility to epoxide-induced cytogenetic damage. Cancer Res 50: 15851590

Williams DMJ, Smith PM, Taylor KJW, Crossley IR, Duck BW (1976) Monitoring liver disorders in vinyl chloride monomer workers using greyscale ultrasonography. Br J Ind Med 33: $152-157$

Yu MW, Gladek-Yarborough A, Chiamprasert S, Santella RM, Liaw YF, Chen CJ (1995) Cytochrome P450 2E1 and glutathione S-transferase M1 polymorphisms and susceptibility to hepatocellular carcinoma. Gastroenterology 109: 1266-1273 